\title{
Learning Mathematics Through Mathematical Modelling Processes Within Sports Day Activity
}

\author{
${ }^{1}$ Sakon Tangkawsakul, ${ }^{2}$ Nuttapat Mookda, $\&{ }^{3}$ Weerawat Thaikam \\ ${ }^{1}$ Faculty of Education, Kasetsart University, Bangkok, Thailand \\ ${ }^{2}$ Directorate of Education and Training, RTAF, Thailand \\ ${ }^{3}$ Faculty of Education, Nakhonsawan Rajabhat University, Nakhonsawan, Thailand \\ Is.tangkawsakul@gmail.com
}

\begin{abstract}
Applying mathematics in real-life situations is an important objective of mathematics education. Yet in Thailand, the students' ability to connect mathematics to real-life situations is insufficient. In this study, we adapted the school sports day to provide opportunities to relate real-life situations with mathematical knowledge and skills. This study aims to describe the students' responses and the teacher's interaction during a modelling task. The designing of the modelling task, inspired by the realistic Fermi problems, involves collaboration between mathematics teachers and educators and the participation of 10th grade students. The task is set in the context of bleacher in the school sports day. Each experiment's modelling task lasted for 45 minutes and was conducted in the one-day camp with 45 students. Data were collected through observation, interview, and written task before being analysed through content analysis. The results showed that the students who had no previous mathematical modelling experience engaged in mathematical modelling processes with their friends under the guidance and support of the teacher. Most of them were able to think, make assumptions, collect data, observe, make conjectures and create mathematical models to understand and solve the modelling task.
\end{abstract}

Keywords: mathematical modelling, realistic Fermi problems, sports day, real-world problems.

\section{Introduction}

In several countries, the promotion of science, technology, engineering, and mathematics (STEM) education is an essential educational topic that enables students for a scientific and technological society. One of the important teaching and learning approaches for the transition to STEM education and interdisciplinary mathematics education is mathematical modelling (Borromeo Ferri \& Mousoulides, 2017; Tezer, 2019). Besides, mathematical modelling can be considered good examples of STEM integration (Kertil \& Gurel, 2016).

Actually, mathematical modelling supports mathematical learning and enables students to deal with real-world problems (Blum \& Borromeo Ferri, 2009). Although the ability to apply mathematical knowledge and solve real-world problems has been recognised in the Basic Education Core Curriculum in Thailand, both students and teachers have little experience in mathematical modelling. Moreover, about 50 per cent of 15-year-old Thai students did not achieve the international basic proficiency level (level 2) at mathematical literacy in PISA 2009 and PISA 2012. These results show that Thai students lack the ability to connect realworld problems with mathematics (Klainin, 2015).

Hence, we were interested in observing and describing how the students respond to modelling activities. To achieve that purpose, we started by designing tasks to encourage students to connect inside and outside classroom mathematics and foster their ability to solve 
real-world problems with mathematical modelling processes. We adapted the idea of using realistic fermi problems about the bleacher in the school sports day, closely related to Thai students' experiences, to introduce mathematical modelling in upper secondary mathematics following Ärlebäck and Bergsten (2013). The questions we aim to answer in this paper are as follows:

1. How does the teacher interact with students during the mathematical modelling task?

2. How do the students respond to mathematical modelling task?

This study aims at describing the students' responses to the modelling task and the teacher's interaction with their students during mathematical modelling processes.

\section{Theoretical Framework}

\section{Mathematical modelling processes}

Mathematical modelling is an essential educational topic that fosters the students' ability to deal with real-world problems (Blum \& Ferri 2009). Mathematical modelling processes showed how the process connects real-life contexts and mathematics content. It might look different and highlight different perspectives depending on the research's purpose and focus (Blum, Galbraith, \& Niss, 2007). In this study, we adapted an ideal modelling process that includes six phases allowing cognitive activities to solve the modelling tasks described by Ferri (2006) as shown in Figure1.

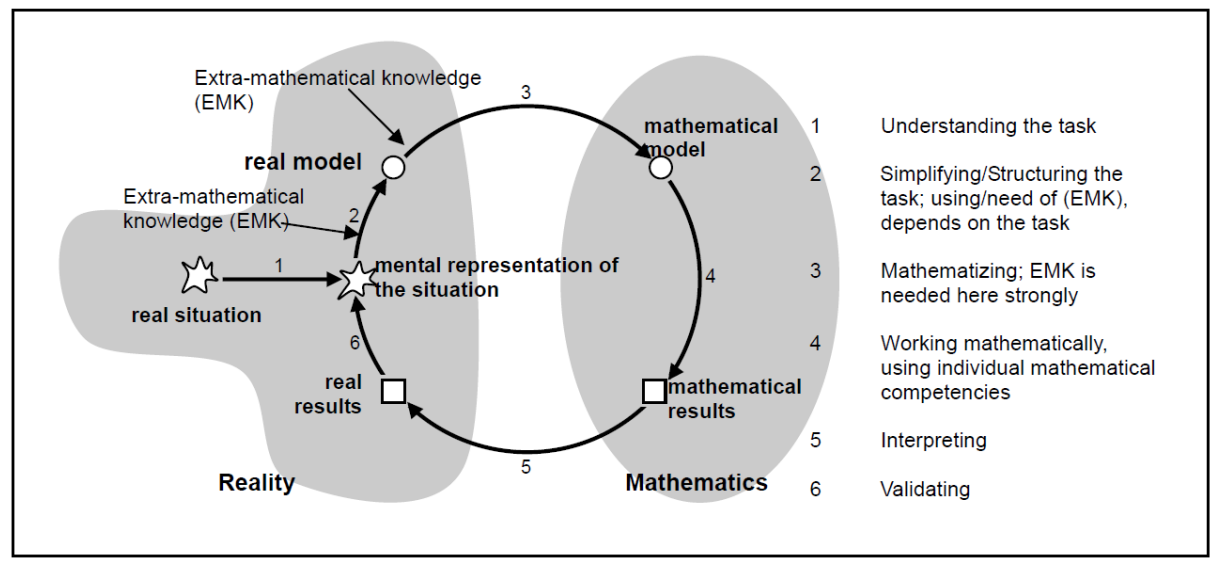

Figure 1. Modelling cycle under a cognitive perspective described by Ferri (2006).

Based on Ferri's model, modelling processes consisted of two components: phases and transitions that intertwined between two domains, reality and mathematics. The six phases comprise a real situation, mental representation of the situation, real model, mathematical model, mathematical result and real result. Simultaneously, the transitions include six activities: understanding the task, simplifying/structuring the task, mathematising, working mathematically, interpreting and validating. 


\section{The realistic Fermi problems}

There are several important principles in model-eliciting activities (Lesh, Hoover, Hole, Kelly, \& Post, 2000). Two of them are: 1) model construction principle, as in the problem must evoke the need to mathematise and model meaningful situation to solve a problem, and 2) reality principle, as in the problem need to be relevant and meaningful to the students; the kind that they might encounter in real life. Effective modelling activities should also be open, in a sense that there are no predetermined right answers. The students have the freedom to choose the most suitable mathematical concepts they will use to solve the problem.

One of the notions that fit these principles is the Fermi problem. The term Fermi problem originates from the 1938 Italian Nobel Prize winner in physics Enrico Fermi (1901-1954). He had posed and solved problems like how many piano tuners are there in the US. He demonstrated that using a few reasonable assumptions and estimates could give accurate and reasonable answers (Efthimiou \& Llewellyn, 2007). The Fermi problem was always answered by simplifying, making assumptions, estimating, and doing rounded calculations while the exact answer is often not available. It is the main important feature of the Fermi problem-solving process (Sowder, 1992).

According to Ärlebäck and Bergsten (2013), the characters of Realistic Fermi Problems was described as follow:

1. the realistic Fermi problem does not necessarily demand any specific pre-mathematical knowledge. All individual students or groups of students can access and solve the problem;

2. the realistic Fermi problem is more than just an intellectual exercise. The context is realistic and presents clear real-world connection;

3. the realistic Fermi problem is open. The specifying and structuring of the relevant information and relationships are needed to tackle the problem;

4. the realistic Fermi problem does not show the numerical data. The problem solver needs to make reasonable estimates of relevant quantities, and

5. the realistic Fermi problem is to promote group discussion.

\section{Design of the Study}

The question was posited as the students' responses to the modelling task and teachers' interaction with their students during each mathematical modelling processes.

\section{Participants}

The study participants were divided into two groups. The first comprised three mathematics teachers and two mathematics educators interested in mathematical modelling, while the second consisted of 45 tenth grade students. These students had no previous experience in mathematical modelling in the classroom based on the Basic Education Core Curriculum of Thailand.

\section{Methods}

In designing the bleacher task, the task's objectives were to encourage students to connect inside and outside classroom mathematics and enhance their ability to solve real-world problems with mathematical modelling. We designed and validated the task by collaborating 
with three mathematics teachers and two mathematics educators interested in mathematical modelling. The task validation is based on four notions below.

1. The characters of Realistic Fermi Problems described by Ärlebäck and Bergsten (2013).

2. The information on the students' experiences and prior knowledge relevant to the task. This information was collected by conducting interviews with mathematics teachers who had experience teaching these students. The interview was important to confirm that the bleacher in the school sports day problem is both encouraging and engaging context for the students.

3. The framework for designing mathematical modelling learning experience described by Ang (2018).

4. The modelling cycle under a cognitive perspective described by Ferri (2006).

The bleacher task is as follows:

The bleacher task:

In the school sports day, all students were organised into several groups with wide-ranging sports and varied performance abilities. Each group was labelled by colour to participate in sports, cheerleading and bleacher cheer show performance.

You and your team members are given the relevant materials. Draw your own conclusions and answer these following questions:

1. How many students that can reasonably be arranged in the bleacher for cheer show performance?

2. What is the relationship between the sizes of bleacher and the numbers of students?

In implementing the bleacher task, a qualitative approach was adopted. The teacher's role (one of the authors) was as a facilitator, encouraging and guiding a small group of students to deal with the bleacher task. The 45 students were divided into eight groups of $4-5$ students with wide-ranging abilities in mathematics. Each experiment lasted for 45 minutes and was conducted with two groups of students in the one-day camp. The students' responses and teachers' interactions during mathematical modelling process were gathered through observations, written work, and interviews. The data were analysed by content analysis according to the mathematical modelling framework by Ferri (2006). The result is presented in a narrative description.

\section{Results and Discussion}

This study showed the students' responses to the bleacher task and the way that teacher interact with their students during each mathematical modelling process as follows.

Initially, the teacher and students met at bleacher in the school playground (Figure 2). The teacher asked the student about their experience with the bleacher on the school sports day. All of the students participated in the conversation about the bleacher. The students were given the bleacher task. The teacher then gave the students time to understand the task and discuss what the problem wanted to know with their friends (Figure 3). 


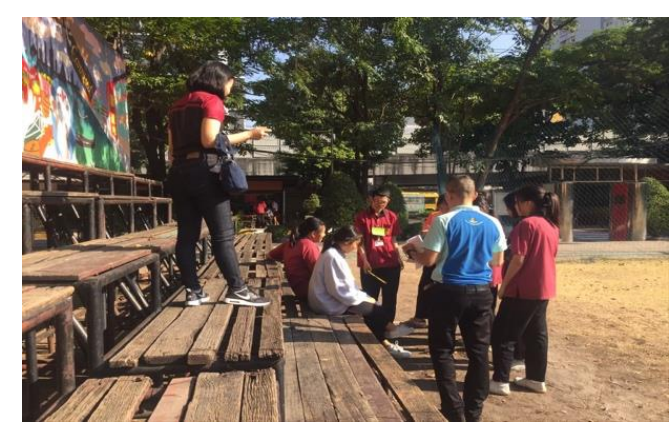

Figure 2. Meeting at bleacher in the school playground.

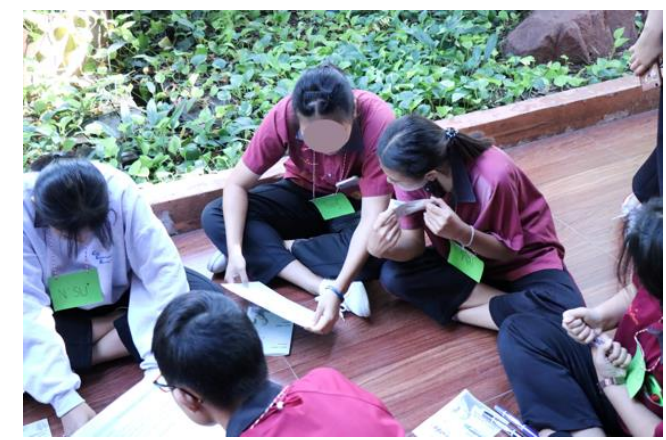

Figure 3. Understanding the task.

Next, the teacher discussed the factors related to determining the number of students sitting on the bleacher to guide students to simplify the task and make assumptions. Most of the students' assumptions were as follows:

1. each student must be seated according to the size of the bleacher, fit, and not overcrowded;

2. the sitting position must look neat and straight; and

3. the sitting posture must be the same.

Besides, one group assumed the distance between each student must be appropriate for movement in performance. Then, the teacher asked the students what the relevant and necessary data is, which we have to search for solving the problem. Some groups of students identified some unnecessary data (width and height of the bleacher). In these cases, the teacher asked them how the bleacher's width and height were relevant and necessary for solving the problem. They discussed and found that the bleacher's width and height were not necessary (Figure 4).

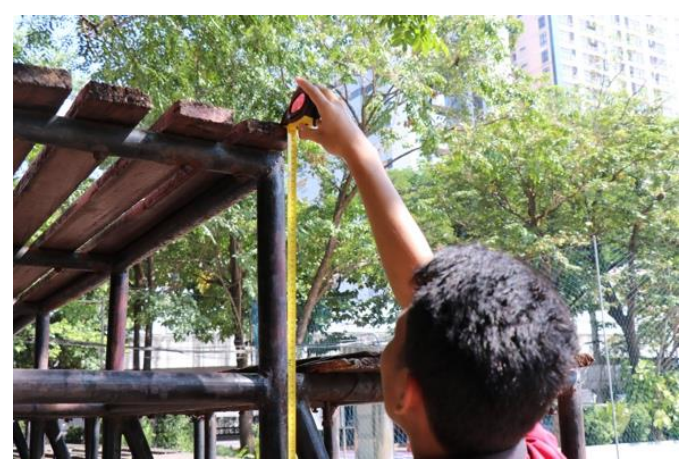

Figure 4. Identifying some unnecessary data. 
On the other hand, most students were available to identify the relevant and necessary data (the size of the student who sat on a bleacher or area for sitting per person) as shown in Figure 5. During their search for the data, two groups have interesting reasons for determining the size of the student which connects between real-world and mathematics such as knowing the height and weight of the student to choose the right seated student, fit and balance to the bleacher, and sitting in a straight line.
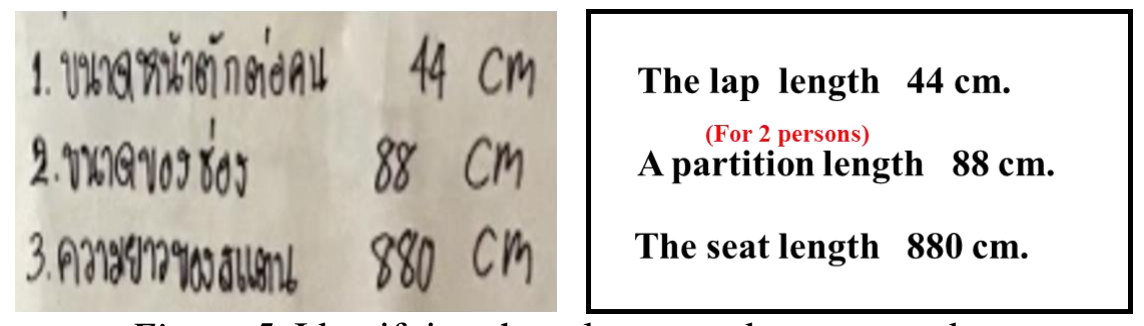

Figure 5. Identifying the relevant and necessary data.

After that, the teacher guided the students to create a real model which simplified and structured students' mental picture (Figure 6). They used drawings and diagrams to represent the bleacher's size, sitting position, and distance between each student. Some student groups identified conditions about sitting posture and performance on the bleacher such as space for placing cheer prop and students' size and height.

Students' assumption

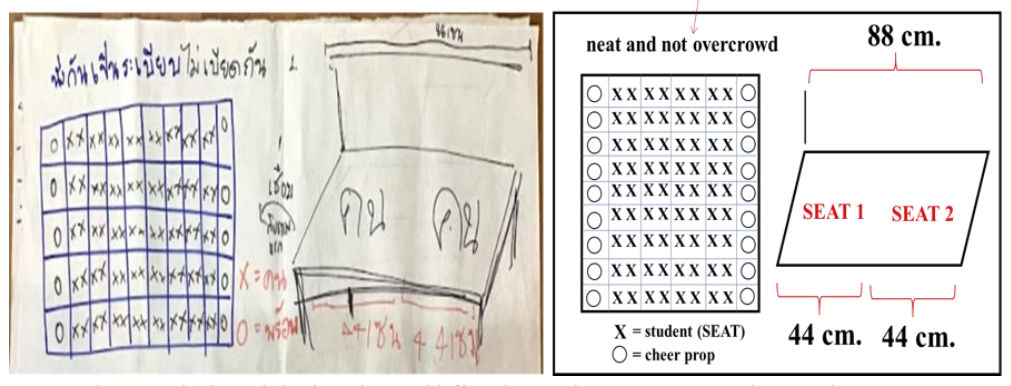

Figure 6. A real model which simplified and structured students' mental picture.

The teacher then allowed the students time to discuss and think about the appropriate mathematical knowledge and concepts related to solving the problem. Moreover, they tried to sit (Figure 7) and measure by using the measuring tape (Figure 8) to collect data, observe, make conjectures, and create mathematical models to solve the problem under the teacher's guidance and support.

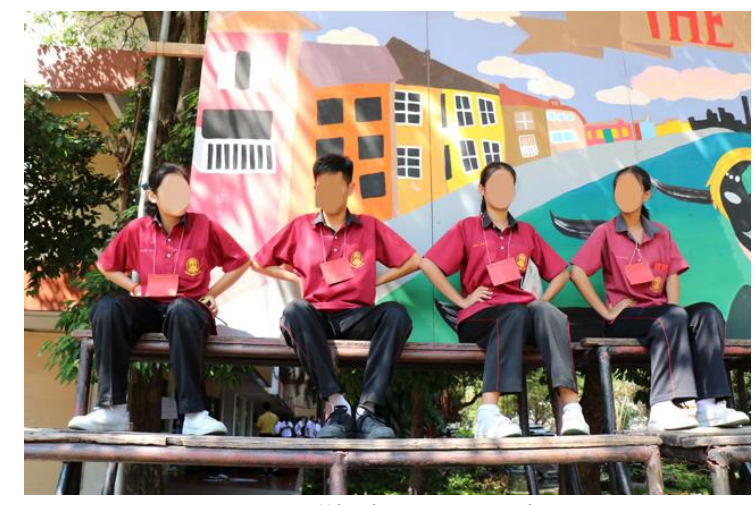

Figure 7. Sitting experiment. 


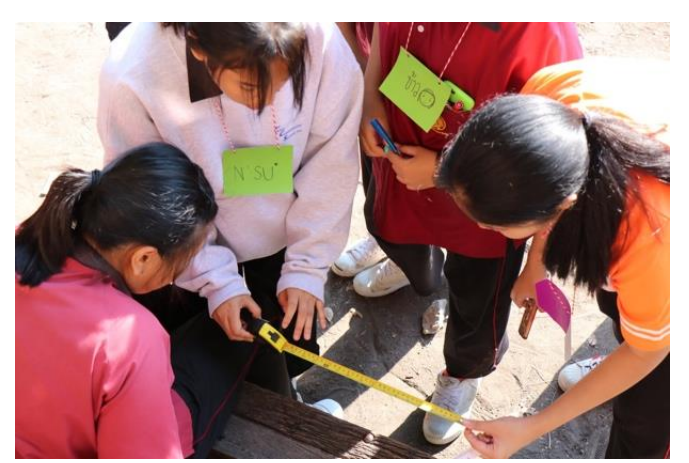

Figure 8. Measuring using the measuring tape.

The students used the bleacher sizing and the sitting experiments and obtained measurement from the different width of the body (the lap and shoulder). Some groups used either the actual measurements (2 decimal places) or approximate values from their measurements which round it to integers to make calculations easier (Figure 9). Finally, some groups used only one value from one measurement, while others choose to use the mean of values from their repeated measurements. Next step, the students worked mathematically based on unit rate ideas to represent the relation of seat length per person, then created the relation between seat length and the number of the students in general term. The teacher asked the students to interpret and check the mathematical results.
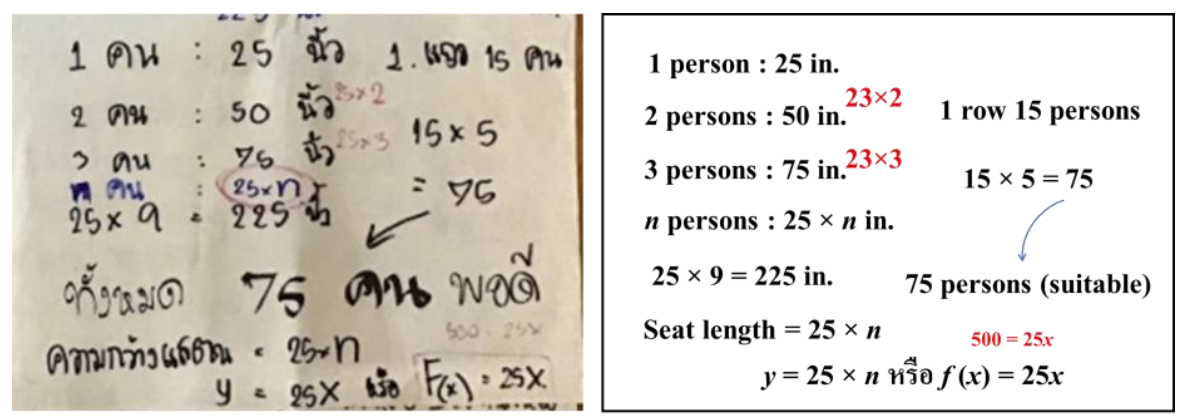

Figure 9. Working mathematically.

Furthermore, students validated the result by comparing the solution with their experience. Finally, they have to share their problem-solving processes and explain the meaning of all variables in the equation based on the real-world situation to others, as shown in Figure 10. In this step, we found that some groups have mistaken in interpreting. For example, the students used the equation $(y=25 x)$ to model the general relation between seat length $(y)$ and the number of students $(\mathrm{x})$.

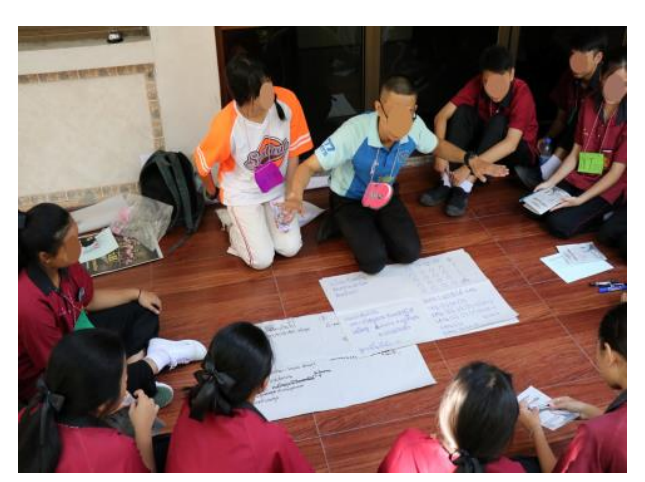

Figure 10. Sharing their problem-solving processes. 
In this case, the teacher asked students to think about applying the student's model in a normally real-world context because actually we knew the size of the bleacher first then found the number of students. So, the teacher tried to lead students to concern about the independent variable (input) and the dependent variable (output) based on the real-world situation.

It was evident from the result that the use of open and complex problems for a diverse solution, like Fermi problems, can be an effective modelling task. The problem can elicit the cognitive processes essential to mathematical modelling (Ferri, 2006) from the students. This is in line with the studies by Peter-Koop (2004) and Ärlebäck (2009), which demonstrate Fermi problems' potential to engage the students and encourage them through multiple modelling cognitive stages.

\section{Conclusion}

The description of the students' response and the teacher's interaction shows that typical Fermi problem, which is open, ill-structured, and possesses high-complexity, can effectively engage the students throughout the modelling task and elicit an appropriate cognitive response. The real-world context that is closed and related to students' experience also enhances students' engagement in the mathematical modelling processes with their friends under the teacher's guidance and support. It is recommended for the teacher to plan to deal with students in the modelling activity to know about the phases and their transitions in each modelling cycle because it is essential to guide and support them in dealing with a real-world problem.

\section{References}

Ang, K. C. (2018). Mathematical modelling for teachers: Resources, pedagogy and practice. London, England: Routledge.

Ärlebäck, J. B., \& Bergsten, C. (2013). On the use of realistic Fermi problems in introducing mathematical modelling in upper secondary mathematics. In Lesh R., Galbraith P., Haines C., Hurford A. (eds) Modeling Students' Mathematical Modeling Competencies (pp. 597-609). Dordrecht, Netherlands: Springer. doi: 10.1007/978-14419-0561-1_52

Blum, W., \& Borromeo Ferri, R. (2009). Mathematical modelling: Can it be taught and learnt? Journal of Mathematical Modelling and Application, 1(1), 45-58.

Borromeo Ferri, R. (2018). Learning how to teach mathematical modelling in school and teacher education. Springer International Publishing. doi: 10.1007/978-3-319-68072-9

Borromeo Ferri, R., \& Mousoulides, N. (2017). Mathematical modelling as a prototype for interdisciplinary mathematics education? - Theoretical reflections. In T. Dooley \& G. Gueudet (Eds.), Proceedings of CERME 10 (pp. 900-907). Dublin, Ireland: ERME. 
Efthimiou, C. J., \& Llewellyn, R. A. (2007). Cinema, Fermi problems and general education. Physics Education, 42(3), 253-261. doi: 10.1088/0031-9120/42/3/003

Kertil, M., \& Gurel, C. (2016). Mathematical modelling: A bridge to STEM education. International Journal of Education in mathematics, science and Technology, 4(1), 44-55. doi: 10.18404/ijemst.95761

Sowder, J. T. (1992). Estimation and number sense. In D. A. Grouws (Ed.), Handbook of research on mathematics teaching and learning: A project of the National Council of Teachers of Mathematics (p. 371-389). Reston, VA: The National Council of Teachers of Mathematics, Inc.

Sunee, Klainin. (2015). Mathematics education at school level in Thailand the developmentThe impact - The dilemmas. Retrieved from https://library.ipst.ac.th/handle/ipst/959

Tezer, M. (2019). The Role of Mathematical Modeling in STEM Integration and Education. In K.G. Fomunyam (Ed.) Theorizing STEM Education in the 21st Century. IntechOpen. doi: 10.5772/intechopen.88615 
114 Southeast Asian Mathematics Education Journal, Volume 10, No 2 (2020) 